\title{
Teacher Questions in a Content-based Classroom for EFL Young Learners
}

\author{
Junyi Meng \\ School of Foreign Languages, Guiyang University, Guiyang 550005, China \\ Email: jymeng66@hotmail.com \\ Tao Zhao \\ School of Foreign Languages, Guizhou Normal College, Guiyang 550018, China \\ Email: tzhao65@hotmail.com \\ Athithouthay Chattouphonexay \\ Faculty of Education, National University of Laos, Vientiane 7322, Laos \\ Email: athithouthay@yahoo.com
}

\begin{abstract}
Questions are the most common form of interaction between teachers and students in classroom teaching. However, while many studies go to questioning techniques in ESL/EFL classrooms, few turn to content-based classrooms, especially for young learners. The goal of this study is to explore types and functions of questions that teachers use in Content-Based Instruction (CBI), and how teachers deal with the non-responded questions. The participants were 16 Grade-three students and 1 teacher teaching "Science" in English from Plookpanya School in Thailand. A purely qualitative method was adopted through the use of classroom observations and interviews. The results showed that the teacher questions were referential and display questions. However, only display questions were used when dealing with teaching and learning. They serve several functions such as to elicit information, to check learners' understanding, etc. In addition, six question modification strategies were employed when dealing with non-responded questions. Pedagogical implications for the effective use of teacher questions in content-based classrooms for young learners are also discussed.
\end{abstract}

Index Terms - teacher questions, content-based classroom, TEFL, young learners

\section{INTRODUCTION}

Questions are the most common form of interaction between teachers and students in classroom teaching. Lynch (1991) characterized a question as an utterance with a particular illocutionary force, and Quirk et al (1985, cited in Shomoossi, 2004) defined a question as a semantic class used to seek information on a specific subject. In terms of teacher questions, Tsui (1992) claimed that teacher questions are all types and structures of utterances classified, either syntactically or functionally, as questions asked by teacher before, during, and after instruction in order to elicit responses from the students (Jansem, 2008).

Several categories are produced for teacher questions. Hargie (1981) classified teacher questions into the recall/process questions and the closed/open questions. Long and Sato (1983) and Brock (1986) have worked on the role of teacher's question types: display questions and referential questions. Wilen (1991) revealed that teachers spend most of their time asking low-level cognitive questions, which concentrate on factual information that can be memorized, while high-level-cognitive questions which requires students to use higher order thinking or reasoning skills is quite demanding. Interestingly, teacher questions can be viewed as pedagogical questions, which consist of yes/no, open-ended, convergent, and divergent questions (Gabrielatos, 1997). Whatever names are used for their types, teacher questions can, in general, be grouped into two: one is for facts, such as recall, closed, display, low-level cognitive, yes/no, and convergent questions; the other for opinions, namely, process, open, referential, high-level cognitive, open-ended, and divergent questions.

Teacher questions may serve different functions which are listed by such researchers as Brown and Wragg (1993) "to arouse interest and curiosity concerning a topic; to focus attention on a particular issue or concept; to develop an active approach to learning; to stimulate pupils to ask questions of themselves and others"; Nunan and Lamb (1996) "to check learners' understanding, to elicit information, and to control their classrooms"; Peacock (2001) "to find out what pupils do or do not know and understand; to remind them about work completed in a previous lesson; to challenge, stimulate and develop their thinking"; Morgan and Saxton (1991, cited in Brualdi, 1998 ) "to keep their learners involved during lessons; to express their ideas and thoughts; to enable learners to hear different explanations of the material; to help teachers to evaluate their learners' learning and revise their lessons when necessary"; O.Fakeye (2007)"focusing 
attention; exercising disciplinary control in the course or instruction; encouraging students' participation; moving the lesson forward", etc.

In fact, teacher questioning has been identified as a critical and challenging part of teachers' work (Boaler et al, 2004). The act of asking a good question is cognitively demanding, and requires considerable pedagogical content knowledge (Shulman, 1987). Good questioning is both a methodology and an art; there are certain rules to follow (Ornstein \& Lasley, 2000). Questioning becomes a key method of altering the level of challenge provided and determining the progress made in lessons, particularly in a content-based classroom.

Content-based instruction (CBI) has been a growing part of English language teaching curriculum planning in the US K-12 education for more than a decade (Crandall \& Tucker, 1990). In countries where English is a second or foreign language, CBI should also have a larger role, given the growing numbers of English-medium schools and universities (Owens, 2002). CBI (Brinton et al, 2003) is defined as the integration of particular content with language teaching aims...as well as the concurrent teaching of academic subject matter and second language skills. Three content-oriented instruction models---theme-based model, sheltered model and adjunct model---can be used respectively according to certain criteria such as their applicability to different settings and proficiency levels. "Immersion Education" in CBI also illustrated the effectiveness for kindergarteners to adolescence of instruction which focuses on teaching subject matter through the medium of the second language.

For successful language learning to occur, the language syllabus must take into account the eventual use the learner will make of the target language (Brinton et al, 2003). It is a student's desire to understand and use the content that motivates him or her to learn the language. Even in language classes, students are likely to learn more if they are not simply learning language for language's sake, but using language to accomplish concrete tasks and learn new content (Mehisto et al, 2008). The teaching of rhetoric cannot be divorced from the teaching of content, and therefore English faculty who have little or no knowledge of a discipline cannot adequately teach or response to discipline-specific writing (Swales, 1990).

The process of second language acquisition for young learners is worth researching because good teaching techniques and strategies can lead to their earlier successful language competence. Although in content-based classrooms for young learners the instructors may find content is not so demanding for them, they can implement more feasible patterns to help students with their both content and target language learning.

However, a large number of research studies have been conducted to explore teacher questions in the second or foreign language classroom interaction (Xie, 2007), whereas the studies of teacher questions in content-based classrooms, especially for EFL young learners, have been quite limited. Therefore, this research project aims to explore the content-based classroom for EFL young learners, focusing on teacher questions in order to explore types and functions of questions that teachers use in CBI especially when dealing with content and language focus, and how the teacher deals with the non-responded questions. Qualitative research method was applied in this study for in-depth data collection and thick description. This research provided answers to the following research questions:

1. What types and functions of teacher's questions are found in content-based classroom?

2. How do teachers cope with the non-responded questions?

\section{ReSEARCH METHODOLOGY}

\section{A. Participants}

In this research, the participants were from Plookpanya School, Nakhon Ratchasima, Thailand, including the whole class (16 students) of Grade Three taking the "Science" course in English, and the teacher (1 teacher) teaching the "Science" course in English.

\section{B. Instruments}

The two instruments used for data collection included a classroom observation and an interview. Structured non-participant type of classroom observation was used. The focus of the observations was the types and functions of teacher questions and the techniques the teacher used to cope with non-responded questions. The class was observed by the three researchers for about 6 teaching hours in total. The other instrument was a semi-structured interview for gaining more in-depth information about the purposes of the questions posed during class time. An interview was constructed after class by the three researchers. The interviewee was mostly asked to clarify the reasons why particular types of questions were used and to confirm if the techniques were accurately interpreted. Other supporting instruments for data analysis such as question type form, function form, observation sheets were piloted and modified before the real data collection.

\section{Data Collection}

While collecting data, the researchers took the procedure as follows: Step 1: After doing a review of the related literature, and getting familiar with earlier studies on relevant topics, the researchers made an observation scheme for the study. Step 2: Selecting the participants of the research. Step 3: Non-participant observation and structured observation were selected for data collection purposes. The researchers visited the class, sitting from the beginning to the end of the session, taking notes of teacher questions. The classes were observed as carefully as possible by the 
researchers. Neither the teacher nor the students were let to know about the focus of the study until all observation sessions were finished. Audio-recording the session observed by the researchers were made. Step 4: Semi-structured interview was selected to collect the data for in-depth information. The teacher was interviewed. The researchers interviewed the teacher about the questions she asked in class, and the reasons of her questioning behaviors, especially the ways she used to cope with the non-responded questions. Step 5: After the preliminary data collection from both observation and interview, the data would be analyzed.

\section{Data Analysis}

The process of data analysis involves making sense out of text and image data. It involves preparing the data for analysis, conducting different analyses, moving deeper and deeper into understanding the data, representing the data, and making an interpretation of the larger meaning of data (Creswell, 2003). Data from both the classroom observations and the interview were analyzed scrupulously and meticulously in this study. While analyzing observation data, the researchers followed the steps, namely, 1. Transcribe the interview data; 2. List the teacher questions out of the observation notes; 3 . Validate the raw data with other team members; 4 . Read and code the data individually and then in group; 5. Classify the data in the instruments (check sheets and check lists); 6. Analyze the data; 7. Answer the research questions.

\section{--- Data from the classroom observations}

A total of 183 questions were found in this study. By use of the check sheet, the researchers firstly grouped the questions into YES/NO questions and WH questions in order to see the structural formation of the questions, which might help to analyze the information related to the research topic. 58 YES/NO questions and 125 WH questions were found in this study. For example, "Are small animals eaten by large animals?"; "What's this you can see?"; "Why does it go down?"; "How far is the distance from me to the door?", etc.

This study aims to explore the functions of questions that teachers use in class, so all the coded questions were organized into relevant themes and categories. Four functions were found, they were, "to check learners' understanding"; "to review the content taught before introducing new topic"; "to elicit information"; "to control the classroom." some examples were listed in Table 1.

TABLE1:

SOME EXAMPLES FROM CLASSROOM OBSER VATION

\begin{tabular}{|l|l|l|l|}
\hline $\begin{array}{l}\text { To check learners' } \\
\text { understanding }\end{array}$ & $\begin{array}{l}\text { To review the content taught } \\
\text { before introducing new topic }\end{array}$ & To elicit information & To control the classroom \\
\hline $\begin{array}{l}\text { Fill, What is a predator? (31) } \\
\text { So, what is a predator? (35) ... }\end{array}$ & $\begin{array}{l}\text { So, what is a predator? (35) } \\
\text { A wolf is a predator? (36) ... }\end{array}$ & $\begin{array}{l}\text { What's this you can see? (1) } \\
\text { What's this? Can you see? } \\
\text { on a chain?(2) ... }\end{array}$ & $\begin{array}{l}\text { What's the problem? (4) } \\
\text { Are you listening? (32) ... }\end{array}$ \\
\hline
\end{tabular}

More information kept jumping from the data with the repetitive reading of the transcript. As the types of teacher questions were a core issue in this study, two types were designed to be observed in class. They were display question and referential question. The former is a question which is not a real question but which serves to elicit language practice; while the latter is s a question which asks for information which is not known to the teacher. The researchers analyzed each of the questions the teacher used in class with the help of a checklist, and found all the questions related to the teaching and learning were display questions.

The physical setting in this study was not the regular language learning classroom but a content-based classroom, where 16 Grade-three Thai students were learning "science" in English and the teacher are teaching "science" in English. Teacher questions in this case might be either content-driven or language-driven. However, the researchers found that all the questions were content-driven rather than language-driven.

While analyzing the data, the researchers also found that not all of these teacher questions were responded in class. Based on the contexts where the teacher questions were not responded, the researchers found that there existed three situations. One was related to rhetorical questions (e.g. A wolf is a predator?), another was to control the classroom (e.g. T: (to one of the student) What's the problem? Are you listening?), and the third was related to something new so that the students failed to respond (e.g. T: Who is on the top of the chain?).

Regarding those non-responded questions in the third situation, the teacher modified her questions to elicit response. The researchers grouped the ways the teacher dealt with non-responded questions in this study and labeled them like this: 1. Simplifying questions; 2. Repeating questions with different suprasegmental features; 3. Employing additional questions; 4 Longer wait time for response; 5. Helping with body language; 6. Explaining, Exemplifying, or Answering.

\section{--- Data from the Interview}

While analyzing the data from the interview, the researchers firstly transcribed the interview, and then coded the statements relevant to the research topic after reading them in detail. Themes and categories jumped out of the data, and the researchers immediately noted them down and labeled them. The categories could be roughly classified into five aspects: 1. Importance of Teacher Questions (e.g. “...it's important for questioning, I think...”); 2. Purposes of Teacher Questions (e.g. " ....with questions, it seems to be that the majority can understand what I am teaching, ... it is a kind of understanding to help them with the content, like position.”); 3.Types of Teacher Questions (e.g. "I think eventually it's important to ask referential questions because they challenge the children more,"); 4. Functions of Teacher Questions 
(e.g. "... with questions, even to check if they understand what we talked about..."); 5. Modification Techniques for Non-responded Questions (e.g. “...they don't understand what I am saying, so I have to simplify the questions into yes or no questions").

Actually, the more the researchers read the statements, the more likely something would be found. Under each category, more subcategories could be discovered and help the researcher to make a deeper analysis. In order to make the categorization as explicit as possible, a conceptual map was adapted to provide the whole view (See Figure 1). In this map, the researchers displayed the data by presenting two-level categories related to the research topic. The first level is the categories about the concept of teacher questions from the teacher. These five categories are named as: Importance of Teacher Questions, Purposes of Teacher Questions, Types of Teacher Questions, Functions of Teacher Questions, and Modification Techniques for Non-responded Questions. The second level categories are those subcategories under each of them, helping to support the first level categories.

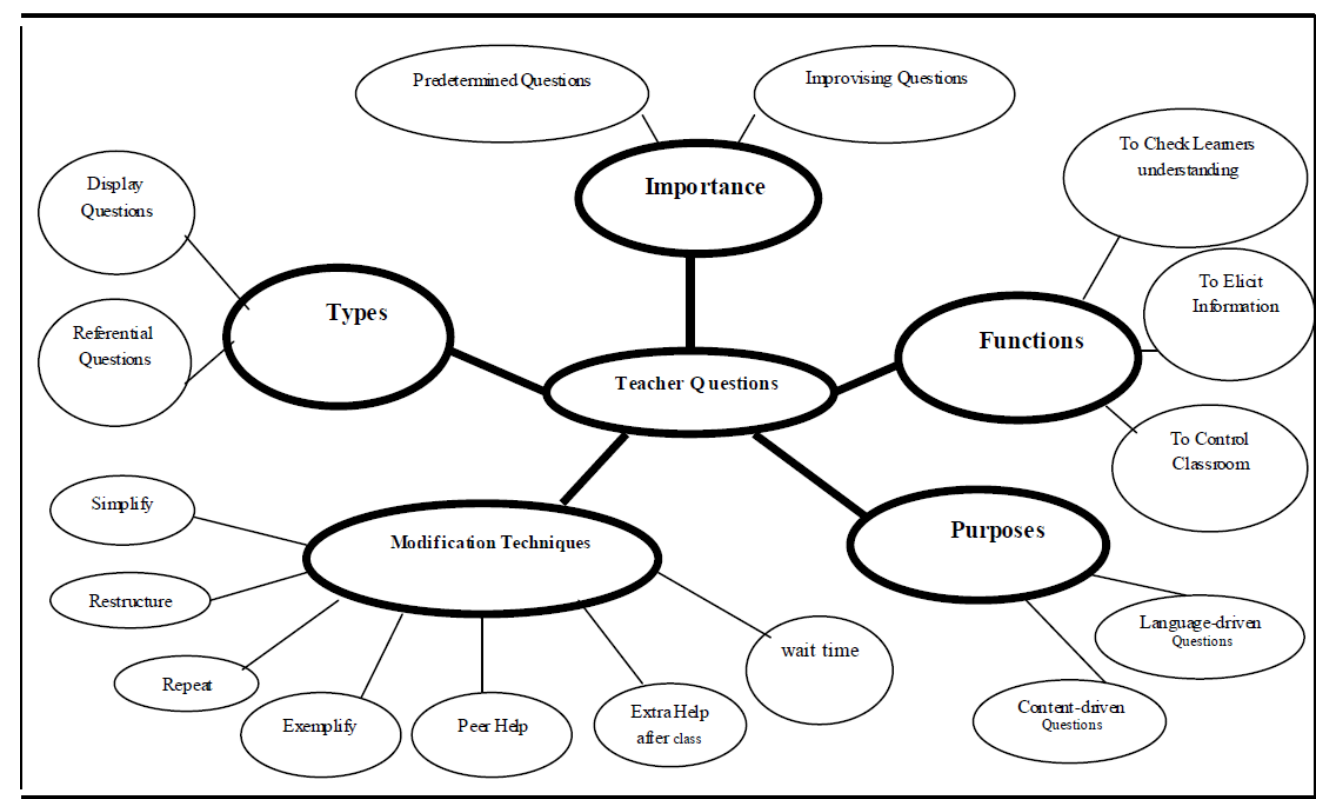

Figure 1: The Concept Map of Teacher Questions

\section{RESULTS}

In this study two research instruments, non-participant classroom observation and semi-structured interview, were adopted for collecting data, and the analysis of the data from these different sources provided the relevant evidences for this research.

In response to the first research question: What types and functions of teacher questions are found in content-based classroom?, the results demonstrated that there were a total of 183 teacher questions, and two types of questions were found: display questions and referential questions, but the ones related to teaching and learning were only display questions. For example,

What's this you can see? (showing a chain to Ss) (1)

Who is the prey of a lion? (pointing at the poster on the board) (40)

How does it move? (showing a toy car to Ss) (108)

Can you feel gravity right now? (when Ss sit at the desk )(120)

Referential questions in this study were not directly related to the content both the teacher and the students were teaching and learning in class. For example,

What do you think of your lunch today, Gain?

Actually the topic they were discussing was the "motion" rather than lunch. In order to help the students understand what the motion was, the teacher asked "when you go down for lunch, what do you have to do?" and the students answered "in motion." However, two students began talking about what they had for lunch without following the teacher, so the teacher used this question.

Regarding the functions of teacher questions, the researchers found that nearly each of the questions that the teacher asked in class served a certain function. Four functions were found: to check learners' understanding; to review the content taught before introducing new topics; to elicit information; to control the classroom. For example,

Fill, what is a predator? (31) (to check learners' understanding)

A lion is a predator? (37) (to review the content taught before introducing new topics)

What's this you can see? (1) (to elicit information) 
Are you listening? (32) (To control the classroom)

In response to the second research question: How do teachers deal with the non-responded questions?, the results showed that in a total of 183 questions, 70 questions the teacher asked were not responded by the students. These non-responded questions could be classified into two groups: 1 . Related to classroom management; 2 . Related to teaching and learning.

The first group would be discarded for further investigation because they were just for arousing the students' attention. For example,

What's the problem, Fill? (4)

Are you listening? (32)

The second group of questions was related teaching and learning. For example,

What's energy? Ss: No response (7)

What is your position right now? Ss: No response (74)

How can you make it go with gravity? Rhetorical question (172)

How can you make it fall? Rhetorical questions (173)

Some questions in this group were challenging for the students because they might involve something new, others were the questions that the teacher used to review the content before moving on to a new topic, they were kinds of rhetorical questions which the teacher did not expect the students to answer.

For those real "non-responded" questions, which refer to the ones related to something new, the researchers found that the teacher was trying to find some modification strategies or techniques to adjust them to be understood. The ways categorized from the observation data included six, and those from the interview data involved seven. Most of these categories might be overlapped and supportive of each other. (See Table 2)

TABLE 2:

SOME EXAMPLES FROM INTERVIEW DATA

\begin{tabular}{|c|c|}
\hline Non-responded Teacher Questions & Modification Techniques \\
\hline $\begin{array}{l}\text { T: What is your position right now? } \\
\text { Ss: No Response (T simplifies the question into "where are you now?" ) } \\
\text { S1: in school; } \\
\text { S2: in a chair }(74)\end{array}$ & Simplifying questions \\
\hline $\begin{array}{l}\text { T: What is the direction? } \\
\text { Ss: No Response (T asks the students to repeat after her..., T asks again "What is } \\
\text { the direction?") } \\
\text { Ss: up and down, east and west. (81) }\end{array}$ & $\begin{array}{c}\text { Repeating questions } \\
\text { with different suprasegmental feature }\end{array}$ \\
\hline $\begin{array}{l}\text { T: Can you label the wave? } \\
\text { Ss:No response (T employs additional question “Can you label crest or trough?”) } \\
\text { Ss: Yes (148) }\end{array}$ & Employing additional questions \\
\hline $\begin{array}{l}\text { T: Fill (a student's name), what is gravity? } \\
\text { Fill: No Response ( T waits for a while) } \\
\text { Fill: pull (119) }\end{array}$ & Longer wait time for response \\
\hline $\begin{array}{l}\text { T: How can you stop it? } \\
\text { Ss: No response. (T gestures with hands, rulers, fingers") } \\
\text { Ss: with hands, rulers, fingers (170) }\end{array}$ & Helping with body language \\
\hline $\begin{array}{l}\text { T: What is a predator and prey? } \\
\text { Ss: No response (T explains) } \\
\text { Ss: small bird (60) } \\
\text { T: What's energy? } \\
\text { Ss: No response (T exemplifies: when you eat apples, you get energy) } \\
\text { Ss: by eating (7) } \\
\text { T: What kind of wave is microwave? } \\
\text { Ss: No response (T answers: heat wave) (157) }\end{array}$ & Explaining, Exemplifying, or Answering \\
\hline
\end{tabular}

\section{DisCUSSIONS, IMPLiCATIONS AND CONCLUSIONS}

\section{A. Discussions}

First of all, the results in this study showed that both display questions and referential questions are found, but display questions are much more than referential ones, and those related to content teaching and learning are only display questions. The researchers found that three reasons were responsible for the fact: 1. the teacher's assumption. The teacher thought that the students could not do it, but actually a couple of top students could answer referential questions, the teacher was not trying it because of her assumption. 2. The students' language proficiency. The students were the beginners, and most of them were in low language proficiency. 3 . The content of the class. The class is for the science course in CBI, more science facts rather than opinions or comments were needed in this course.

From the literature review, in most cases, display questions are adopted more than referential questions. Long and Sato (1983) and Pica (1987) concluded that teachers in ESL classes ask more display questions than referential questions. Some researchers encourage teachers to use referential questions, while others claim that display questions are important as well. Richards and Schmidt (2003) stated that it has been suggested that one way to make classes more 
communicative is for teachers to use fewer display questions and more referential questions. However, it seems that the use of display questions can encourage language learners especially beginners to get interested. It may also help teachers provide comprehensible input for learners (Shomooshi, 2004). Besides, Lier (1988) points out that "such [display] questions have the professed aim of providing comprehensible input and of encouraging early production. I shall suggest by and large, what gives such question types their instructional, typically L2-classroom character is not so much that they are display rather than referential, but that they are made with the aim of eliciting language from the learners." As the participants in this study were the young learners of Grade Three, some factors related to their psychological situations should be considered. Li et al (2004) stated that English becomes a headache to a large number of young learners who suffer repeated frustration and in learning it, which is, in turn, detrimental to their self-esteem and confidence. Chuska (1995) also mentioned that when questions such as those mentioned (referential) are asked, students will usually not know how to respond and may answer the questions incorrectly. Thus, their feelings of failure may cause them to be more hesitant to participate in class. Therefore, in terms of question types, this study suggests that display questions play important roles in enhancing psychological support and facilitating cognitive process for EFL young learners at the early stage.

Secondly, the results showed that four functions were found in this study, and they were consistent with the literature reviewed by the researchers. These four functions emerged from the data in this study were mostly in line with the function categories presented by Nunan and Lamb (1996) and others. It was also found that there is some relationship between the types and the functions of teacher questions. For example, referential questions cannot be used to control the classroom. This is because referential questions ask for information that the teacher does not know (Lynch, 1991). It requires interpretation and judgment on the part of the person who it is directed towards (Shomossi, 2004). Therefore, to control the classroom does not need the high order thinking question (referential question), this specific function of teacher questions is simply for organizing and controlling the class to enable the teaching to be conducted smoothly.

Thirdly, the results in this study showed that six modification techniques were found to cope with the non-responded questions. The taxonomy for the teacher's modification of questions here was quite similar with the framework of Chaudron (1988): 1. Are questions simply repeated? If so, are they repeated more slowly/with different (unnatural?) intonation or stress patterns? 2. Are they rephrased? 3. Does the teacher employ additional questions to clarify the initial one? 4. How long is the wait-time? Two more techniques were found in this study: "Explaining, Exemplifying and Answering" and "Helping with body language." The modification techniques are proved helpful in keeping the instruction interactive and if teachers know enough about the strategies and techniques of modification, he or she will be able to cope with non-responded questions more effectively.

\section{B. Implications}

This study has taken a step in the direction of examining the relationship between teacher questions and the CBI classroom teaching for EFL young learners. It has some pedagogical implications for the way teachers adopt questioning techniques in content-based classrooms.

First, based on the findings, we found that teachers should not limit their questions. The questions asked by the teacher in class should be more than what we found. For example, teachers should use: 1. more referential questions; 2. language-driven questions. On the one hand, referential questions should be adopted more by teachers in class to help students to use higher order thinking or reasoning skills. As what the participant said in this study, "Eventually it's important to ask referential questions." On the other hand, the balance between language-driven questions and content-driven questions ought to be considered. The questions the teacher asked in this study were dominated by content-driven ones. However, students need some explicit teaching for their language learning in natural learning context. So, language-driven questions should be strengthened. In fact, an individual question may serve a particular purpose but if the questions are effectively adopted, they can facilitate the learning and teaching process.

Second, in a teacher training program, different types of modification techniques and the ways how to use them appropriately should be included for those who do not use the strategies to serve the classroom participation. As it was defined, modification techniques are any adjustment, strategy, and attempt teachers employ to simplify or elaborate the original questions addressed to students when the questions fail to receive a response (Jansem, 2008). In order to make the classroom learning and teaching go smoothly, teachers should know the different types of modification strategies for non-responded questions and the proper way they use them.

\section{Conclusions}

This study has been conducted to explore types and functions of questions that the teacher used in CBI especially when dealing with content and language focus; and to explore how the teacher dealt with the non-responded questions. The results from this study have contributed to the field of research on content-based instruction for EFL young learners It is found that the ways in which the teacher asked questions in class had some uniqueness because the students were young learners. Both teachers and young learners could benefit more from teacher questions because the act of asking questions helped teachers keep students actively involved in lessons and stimulate them to keep thinking. Furthermore, future study is needed to investigate the relationship between teacher questions in different courses and different language proficiency in content-based classroom for young learners; and a future study is also needed to examine the 
relationship between the low-grade younger learners and high-grade young learners in the achievement of language learning and content learning.

\section{ACKNOWLEDGMENT}

The authors wish to thank Dr. Sirinthorn Seepho for providing very supportive guidelines. They also want to thank Ms. Kathleen Bischof who was the main participant of this study.

\section{REFERENCES}

[1] Boaler, J. \& Brodie, K. (2004). The Importance, Nature, and Impact of Teacher Questions. presented at the annual meeting of the North American Chapter of the International Group for the Psychology of Mathematics Education, Toronto, Canada, Oct 21,2004 Online. http://www.allacademic.com (accessed 30/6/2009)

[2] Brinton, D. M., Snow, M. A. \& Wesche, M. (2003). Content-Based Second Language Instruction. Michigan Classics Edition. Ann Arbor: the University of Michigan Press

[3] Brock, C.A. (1986). The Effects of Referential Questions on ESL Classroom Discourse. TESOL Quarterly 20: 47 - 59.

[4] Brown, G. and Wragg, E.C. (1993) Questioning. London: Routledge.

[5] Brualdi, A. (1998) Classroom Questions. Washington, DC: ERIC Clearinghouse on Assessment and Evaluation. Retrieved from http://chiron.valdosta.edu/whuitt/files/questions.html (accessed 16/7/2009)

[6] Chaudron, C. (1988). Second Language Classrooms: Research on teaching and learning. Cambridge: Cambridge University Press.

[7] Chuska, K.R. (1995). Improving Classroom Questions. Phi Delta, Kappa Educational Foundation.

[8] Crandell, J \& Tucker, G.R. (1990). Content-based Language Instruction in Second and Foreign Language. In Vivian Sariree (Eds) Language Teaching Methodology in the Nineties. 187

[9] Creswell, J. W. (2003). Research Design: Qualitative, Quantitative, and Mixed Methods Approaches. Thousand Oaks, CA: Sage

[10] Gabrielatos, C. (1997). A Question of Function: Teacher Questions in the EFL Classroom. Paper given at $18^{\text {th }}$ Annual TESOL Greece Convention

[11] Hargie, O., Saunders, C. \& Dickson, D. (Eds). (1981). Social Skills in Interpersonal Communication. London \& Camberry: Croom Helm, 65-91.

[12] Jansem, A. (2008). ESL Teacher Questions and Question Modifications. Ph.D Dissertation, Illinois State University, USA.

[13] Li, Q., W, J. \& Hou,S. (2004). Effective Classroom Management in Young Learners English Teaching. Chinese Journal of Applied Linguistics. 3: 32-33

[14] Lier, S. (1988). The EFL Classroom. EFL Journal 26(3): 196-204

[15] Long, M.H. and Sato C.J. (1983). Classroom Foreigner Talk Discourse: Forms and Functions of Teacher's Questions. TESOL Quarterly 15: 26-30

[16] Lynch, T. (1991). Questioning Roles in the Classroom. ELT Journal 45 (3): 201 - 210.

[17] Mehisto, P., Marsh, D. \& Frigols, M. J. (2008). Uncovering CLIL: Content and Language Integrated Learning in Bilingual and Multilingual Education. Oxford: Macmillan Education

[18] Nunan, D. and Lamb, C. (1996). The Self-Directed Teacher. Cambridge: Cambridge University Press.

[19] Fakeye, D. (2007). Teachers' Questioning Behaviors and ESL Classroom interaction Pattern. Humanities and Social Sciences Journal. 2 (2): 127-131

[20] Ornstein, A. C., \& Lasley, T. J. (2000). Strategies for Effective Teaching. Boston, USA: McGraw Hill Higher Education.

[21] Owens, C. (2002). Content-Based English for Academic Purposes in Thai University. Content-Based Instruction in Higher Education Settings. Edited by Crandall, J. \& Kaufman, D. Alexandria: TESOL

[22] Peacock, M (2001). Pre-service ESL Teachers' Beliefs about Second Language Learning: A Longitude Study. System. 29:177-195

[23] Pica, T. (1987) Second Language Acquisition, Social Interaction and the Classroom. Applied Linguistics 8/1: 8-21.

[24] Richards, J. C. and Schmidt, R. (2003). Longman Dictionary of Language Teaching \& Applied Linguistics. Beijing: Foreign Language Teaching and Research Press

[25] Shomoossi, N. (2004). The Effect of Teachers' Questioning Behavior on EFL Classroom Introduction: A Classroom Research Study. The Reading Matrix 4(2): 24, 46

[26] Shulman, L. S. (1987). Knowledge and Teaching: Foundations of the New Reform. Harvard Educational Review, 57(1), 1-22.

[27] Swales, J. M. (1990). Genre Analysis: English in Academic and research settings. Cambridge: Cambridge University Press.

[28] Tsui, A. (1992). A Functional Description of Questions. In M Coulthard (Eds) Advances in Spoken Discourse Analysis. London: Rutledge.

[29] Wilen,W.W. (1991). Questions Skills, for Teachers. What Research Says to the Teache. Washington D.C. National Education Association.

[30] Xie, C.M. (2007). A Study of Teacher Questioning in Interactive English Classroom. Sino-US English Teaching. 4 (4): 29-37

Junyi Meng was born in Guizhou, China. She is a Ph. D candidate in English Language Studies at School of Foreign Languages in Suranaree University of Technology, Thailand. She received her MA degree in Master of Art in Teaching from Oakland University, Michigan, USA in 1998. She is a faculty member of School of Foreign Languages at Guiyang University, Guizhou, China. Her research interests include language teaching methodology, second language acquisition, and cross-culture comparison. 
Tao Zhao was born in Guizhou, China. He is a Ph. D candidate in English Language Studies at School of Foreign Languages in Suranaree University of Technology, Thailand. He completed his BA degree in English language and Literature in Guizhou Normal University, Guizhou, China, and studied in University of Missouri, St. Louis, USA and Saint Jose State University, San Francisco, USA for more than one year as a visiting scholar. He is a faculty member of School of Foreign Languages at Guizhou Normal University, Guizhou, China. His research interests include language teaching methodology, second language acquisition, and cross-culture comparison.

Athithouthay Chattouphonexay was born in Vientiane, Laos. He is a Ph. D candidate in English Language Studies at School of Foreign Languages in Suranaree University of Technology, Thailand. He received his MA degree in TEFL in Sweden. He is a faculty member of Faculty of Education at National University of Laos. His research interests include language teaching methodology, second language acquisition, and cross-culture comparison. 